\title{
Høykostnadsmedisin - mangler vi åpne og legitime prosedyrer for prioritering?
}

\begin{abstract}
Sammendrag
Bakgrunn. Gapet mellom behov og tilgjengelige ressurser fører til daglige prioriteringer på ulike nivåer i helsetjenesten. Vi bruker innføringen av ny behandling for kolorektalkreft og brystkreft i Norge i 2005 som eksempler for å evaluere om det er etablert prosedyrer for innføring av ny og dyr teknologi som legger til rette for legitime prioriteringer
\end{abstract}

Materiale og metode. I en case-studie ble innføringen av kreftmedisinene cetuximab (Erbitux) og trastuzumab (Herceptin) evaluert ut fra et teoretisk rammeverk - «ansvar for rimelige begrunnelser» laccountability for reasonableness). Kildematerialet er offentlige dokumenter, medieoppslag og vitenskapelige artikler som er relevante for prioriteringsdebatten rundt innføringen av cetuximab (Erbitux) og trastuzumab (Herceptin).

Resultater. Begge sakene illustrerer vanskelige prioriteringsspørsmål der det er legitim uenighet om fortolkninger av data og grunnleggende verdier. De illustrerer mangelen på åpenhet om beslutningene og deres begrunnelser. Cetuximab har dårligere effekt og høyere kostnad enn trastuzumab. Kostnad og effekt ble vektlagt ulikt av aktørene. Det foreligger ingen formell klageadgang for pasienter som ikke får den behandlingen de mener de har krav på.

Fortolkning. På det tidspunkt de to prioriteringssakene ble debattert, var det ikke etablert institusjoner eller gode mekanismer for en åpen og eksplisitt prioriteringsprosess hvor hensynet til legitim uenighet ivaretas.

\section{Kjell Arne Johansson}

kjell.johansson@isf.uib.no

Ingrid Miljeteig

Fagområdet medisinsk etikk

Institutt for samfunnsmedisinske fag

Universitetet i Bergen

Postboks 7804

5020 Bergen

\section{Ole Frithjof Norheim}

Lungeavdelingen

Haukeland universitetssykehus

og

Fagområdet medisinsk etikk

Institutt for samfunnsmedisinske fag

Universitetet i Bergen

Gapet mellom behov og tilgjengelige ressurser (fig 1) (1) fører til daglige prioriteringer på ulike nivåer i helsevesenet. Disse avgjørelsene kan medføre at pasienter nektes potensielt nyttig diagnostikk og behandling. Helse- og omsorgsdepartementet, Helsedirektoratet, Nasjonalt kunnskapssenter for helsetjenesten, de regionale helseforetakene og Legeforeningen har derfor med rette igjen satt prioriteringer på dagsordenen (2-4).

Avveininger rundt fordelingen av helsetjenester befinner seg i et komplekst samspill mellom fag og politikk. Klein og andre har påpekt at profesjonsinteresser kan hindre åpenhet om prioriteringsspørsmål (5-9).

Helseøkonomene er blitt mer synlige i den norske prioriteringsdebatten, og de bidrar til å gjøre verdivalgene eksplisitte (10-13). Gitt budsjettskranker er helsemaksimering bare én grunnleggende verdi som er gjeldende $\mathrm{i}$ denne typen beslutninger. Fordelingsmønsteret, hensynet til de dårligst stilte, diskriminering, tidligere urettferdighet, ikke å gjøre skade, ansvar for egen helse og alder er noen av mange viktige prinsipper og kriterier som kan veies mot det å satse på de tiltak som gir mest helse for lavest mulig kostnad. Ulike aktører er uenige i hvilke hensyn og verdier som skal tillegges mest vekt (14).

I 1997 ble den andre offentlige utredningen om prioritering i norsk helsetjeneste, Lønning II-utredningen, gitt ut. Der ble det anbefalt økt åpenhet og sterkere institusjonalisering av prioriteringsprosessene i Norge (15). Fire allment aksepterte kriterier for prioritering (tab 1) er nedfelt i Lønning IIutredningen og dagens pasientrettighetslov og prioriteringsforskrift $(16,17)$.

Rettferdighetsteorien «ansvar for rimelige begrunnelser» (accountability for reasonableness) gir svar på hvordan avslag på potensielt nyttig helsehjelp kan rettferdiggjøres overfor befolkningen og de som får avslag. Teorien har samme utgangspunkt som Lønning II-utvalget - det er rimelig uenighet om verdispørsmål, og en rettferdig prosess er den beste måten å løse legitim uenighet på $(14,15)$. De fire kravene til en rettferdig og legitim prosess (tab 2) $(9,18)$ må være oppfylt for at avslag på nyttig helsehjelp skal være allment akseptable.

Hensikten med denne artikkelen er å evaluere om det er etablert prosedyrer for innføring av ny og dyr teknologi som fungerer og legger til rette for åpne og legitime prioriteringer. Vi tar utgangspunkt i to norske prioriteringssaker fra 2005, innføringen av cetuximab (Erbitux) og trastuzumab (Herceptin). Begge er dyre kreftmedisiner som ble innført $\mathrm{i}$ ulik takt $\mathrm{i}$ helseforetakene og der leger, ledelse og politikere var uenige $i$ grunnleggende verdispørsmål.

\section{Materiale og metode}

I en case-studie ble innføringen av kreftmedisinene cetuximab og trastuzumab evaluert ut fra det teoretiske rammeverket «ansvar for rimelige begrunnelser». Denne designen er velegnet til å undersøke kontekstavhengig kunnskap, erfaring og handling, særlig når sammenhengen mellom handling og veiledende prinsipper eller rammeverk er uklar (19). Kildematerialet er offentlige dokumenter, medieoppslag og vitenskapelige artikler som var relevante for en norsk kontekst eller kunne relateres til prioriteringsdebatten i 2005/06. Det ble utført søk i ATEKST, Cochrane, PubMed, Kunnskapssenteret og National Institute for Health and Clinical Excellence (NICE).

Den kvalitative analysen er teoristyrt (20). Vi anvender en strukturbasert tilnærming basert på de fire kravene til en rettferdig prosess som er beskrevet i rammeverket (tab 2) $(9,18)$. I lesingen av relevante medieoppslag, publiserte studier og offentlige dokumenter identifiserte vi meningsbærende enheter som passet til strukturen i de enkelte kravene.

\section{Hovedbudskap}

- Det er behov for debatt om bruk av helseressurser ved innføring av nye og dyre medisiner

- Hensyn til effekt og kostnadseffektivitet kan vektlegges ulikt, og faglige og politiske motiver bør tydeliggjøres

- Prioriteringer kan gjøres legitime ved åpne og eksplisitte prosesser med klagemulighet for de involverte 


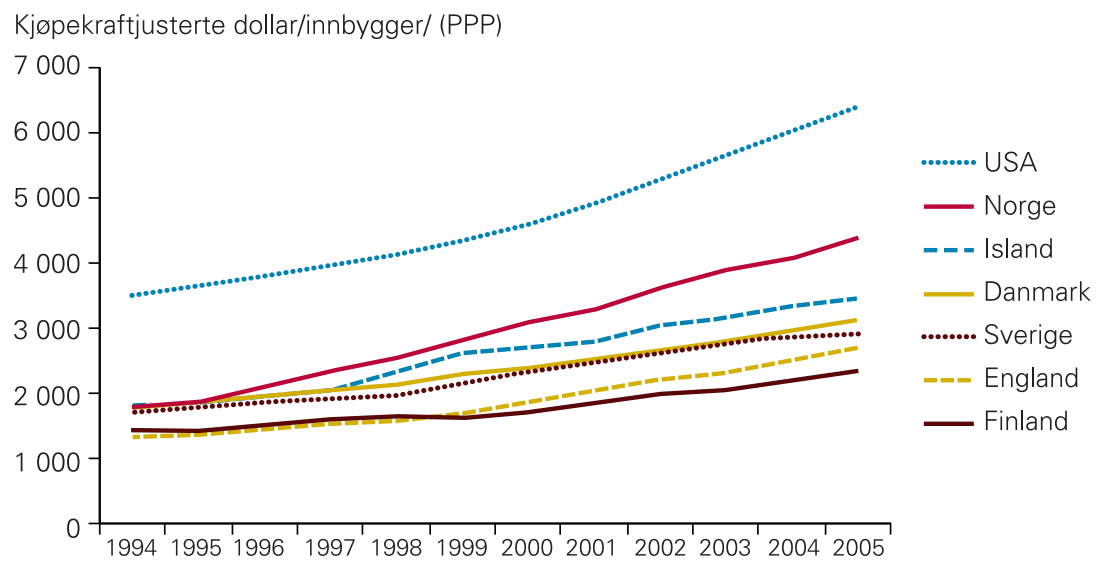

Figur 1 Totalt helsetjenesteforbruk per innbygger per år målt i kjøpekraftjusterte amerikanske dollar (\$ purchasing power parity (PPP)) etter land og år. Basert på 2007-tall fra OECD (1). (๐ OECD, 2007

\section{Resultater}

\section{Innføringen av cetuximab}

I februar 2005 hadde VG og Bergens Tidende en rekke oppslag om en pasient med kolorektal kreft som klaget på at han ble nektet potensielt livreddende behandling ved Haukeland universitetssykehus. Avisene skrev at han ble nektet cetuximab fordi behandlingen var for dyr.

Haukeland universitetssykehus informerte høsten 2005 på intranettet at cetuximab var indisert for kolorektal kreft. Årlig hadde 700 pasienter i Helse Vest denne diagnosen, hvorav 200 av disse kunne være aktuelle for denne behandlingen. Gjennomsnittlig behandlingstid var på omtrent tre måneder, og minimumskostnaden var kr 400000 per pasient. Hvis alle aktuelle pasienter tilhørende Helse Vest skulle få slik behandling, ville det koste ca. 80 millioner kroner i året. Medikamentbudsjettet for Kreftavdelingen ved Haukeland universitetssykehus var på vel 30 millioner kroner i 2005.

Aftenposten skrev i mai 2005 at overlege Tveit ved Ullevål universitetssykehus mente effekten var viktigere enn dårlig økonomi. En av uttalelsene hans lød slik: «Mitt hovedanliggende er at pasientene får god behandling. (...) Vi kan ikke på grunn av dårlig økonomi unnlate å ta i bruk medisiner med dokumentert effekt, når det er konsensus i fagmiljøene om at behandlingen bør brukes, sier Tveit» (21).

Utgangspunkt for debatten var en randomisert, kontrollert studie fra 2004 der man sammenliknet cetuximab monoterapi med kombinasjonsregimet cetuximab pluss irinotecan (22). I 2005 forelå det ingen randomisert, kontrollert undersøkelse der cetuximab monoterapi ble sammenliknet med ingen behandling. Monoterapi ga respons på tumorstørrelsen hos 10,8\%, kombinasjonsterapi hos $22,9 \%(p=0,007)$. Median overlevelsestid var 6,9 måneder ved monoterapi og 8,6 måneder ved kombinasjonsterapi $(\mathrm{p}=0,48)$.

I februar 2005 skrev Bergens Tidende at sykehusets finansieringsordning, innsatsstyrt finansiering, revideres for sjelden og der- med hindret innføringen av cetuximab (23) Tidlig i forløpet måtte derfor hvert enkelt sykehus selv ta medikamentkostnaden. I samme oppslag informerte overlege Mella ved onkologisk avdeling ved Haukeland universitetssykehus at pasientene ikke ble tilbudt medikamentet fordi det var for dyrt (2 millioner kroner per kvalitetsjustert leveår (QALY)) (23). I april 2005 ga helseminister Gabrielsen personlig påbud om at medikamentet skulle bli tilgjengelig og gratis for alle som trengte det (24).

Først høsten 2006 ba Helsedirektoratet om en evaluering av effekt og helseøkonomi fra Kunnskapssenteret, som en del av gjennomgangen av handlingsplanene for kreft. Arbeidet startet like etter, og den helseøkonomiske evalueringen ble oversendt direktoratet i november 2007 (25). I den randomiserte, kontrollerte studien som da forelå, ble ikke cetuximab sammenliknet med standardbehandling. Dette vanskeliggjorde en kostnad-nytte-analyse. I en helseøkonomisk evaluering fra 2006 estimerte Jan Norum at cetuximab i gjennomsnitt ville øke levealderen med 1,7-2 måneder for hele gruppen. Ett vunnet leveår ville da koste $\mathrm{kr} 1680$ 000-2 570000 kr (26).

\section{Evaluering av innføringen av cetuximab}

Apenhet. Pasienten fikk avslag, og det fremgår ingen steder at Helse Vest, Helsedirektoratet eller Helse- og omsorgsdepartementet hadde en offentlig kjent prosedyre for evaluering, innføring og finansiering av nye, lovende kreftmedisiner. Informasjon om behandlingen, forventet nytte og kostnad, ble etter hvert tilgjengelig på sykehusets intranett. Senere kom begrunnelsene frem i mediene, men det var for sent $\mathrm{i}$ prosessen til at man kunne si at kravet om åpenhet var tilfredsstilt. Helseministerens begrunnelse for å prioritere dette behandlingstilbudet er heller ikke gjort offentlig.

Relevans. Begrunnelsen til onkologene ved Haukeland universitetssykehus om ikke å tilby kombinasjonsterapi var i stor grad basert på at helsegevinsten ved bruk av cetuximab var for liten og at medikamentet ikke var kostnadseffektivt. Tveit var uenig i denne begrunnelsen og mente at medikamentet var effektivt nok og kostnaden akseptabel nok til at samfunnet burde finansiere denne typen behandling.

Det var usikkerhet omkring hvor kostnadseffektivt medikamentet var, men ved sykehuset mente man at kostnaden lå på rundt 2 millioner kroner per kvalitetsjustert leveår (QALY) reddet (23). Hva som er akseptabel kostnad, er et verdispørsmål, og følgelig vil det variere hvor mye man er villig til å betale (27). Befolkningen vil være uenige i hva som er de mest relevante grunnene i slike prioriteringsdilemmaer.

Selv om sykdommens alvorlighetsgrad var høy og dette selvsagt påvirket beslutningstakere, klinikere og politikere, var det ingen som eksplisitt vektla alvorlighetsgraden som det mest relevante argument for å innføre denne behandlingen.

Klageadgang og korreksjon. Pasienten kanaliserte sin klage på avslaget til politikerne gjennom mediene. Det foreligger ingen formell klageadgang for pasienter som ikke får høykostnadsbehandling de mener de har krav på. I praksis er det slik at enten må fastlegen be om fornyet vurdering eller pasienten kan be sykehuset om det. Sjelden vil sykehus som sier nei til høykostbehandling nekte pasienter fornyet vurdering ved annet sykehus. Pasienter har også en generell klagerett til Fylkeslegen. Men pasientrettighetslovens rett til å klage på vurderinger om nødvendig helsehjelp gjelder egentlig ikke for avslag på ny og dyr teknologi som inngår i selve behandlingsforløpet $(16,17)$.

Regulering og institusjonalisering. Kunnskapssenteret fikk oppdraget med å evaluere cetuximab sent, lenge etter at politikerne hadde fattet et vedtak. I januar 2007 startet Kunnskapssenteret en systematisk effektgjennomgang og helseøkonomisk evaluering av cetuximab $(16,25)$. Det er ikke etablert institusjoner eller ordninger på foretaksnivå som sikrer at de tre første kravene i tabell 2 blir oppfylt.

Det ble i 2007 publisert en randomisert studie der det ble dokumentert at cetuximab har signifikant effekt på overlevelse og livskvalitet for pasienter med kolorektal kreft (28). Det blir interessant å se hvordan disse mer robuste resultatene påvirker neste fase av cetuximabprioriteringen i Norge.

\section{Innføringen av trastuzumab}

I juni 2005 varslet Norsk Brystcancer Gruppe (NBCG) avdelingsledere ved de fleste kreftavdelinger i Norge om at det var kommet et nytt og svært effektivt medikament $\mathrm{i}$ behandlingen av brystkreft. I oktober 2005 fikk Kunnskapssenteret i oppdrag fra Helsedirektoratet og fagdirektørene i de regionale helseforetakene å vurdere effekt av og kostnad ved trastuzumab som adjuvant behandling av HER2-positiv brystkreft $i$ tidlig fase (29). Klinikkdirektør Øgreid ved universitetssykehuset i Stavanger sa til Stavanger 
Aftenblad: «... som klinikkdirektør ser jeg klart at det må lages nasjonale retningslinjer for bruk av slike kostbare behandlingsformer. Det er fint at fagdirektørene i helseregionene nå ber direktoratet om faglige råd når det gjelder Herceptin. (...) Hva hvis direktoratet sier at dokumentasjonen ikke er god nok? (...) Da vil det bli en voldsom debatt. Men jeg regner med at alle kreftavdelinger vil ta i bruk Herceptin uansett... (30).»

Det var nettopp dette som skjedde. Flere kreftavdelinger hadde tatt i bruk medikamentet allerede før det ble varslet om ekstra utgifter. Dagbladet skrev at Helse Nord vedtok at de ikke skulle tilby trastuzumab inntil rapporten om klinisk nytte og den helseøkonomiske evalueringen fra Kunnskapssenteret forelå. Ved kreftavdelingen ved Universitetssykehuset Nord-Norge bestemte man derimot at man ikke skulle følge dette pålegget (30). Høsten 2005 fikk denne saken lite mediedekning.

Kunnskapsgrunnlaget var to randomiserte studier publisert like før debatten startet høsten 2005. I begge fant man at trastuzumab hadde god effekt på kvinner med HER2-positiv brystkreft i tidlig stadium. Sammenliknet med kontrollgruppen økte den sykdomsfrie overlevelsen signifikant med trastuzumab - fra $75,4 \%$ til $87,1 \%$ og fra $77,4 \%$ til $85,8 \%$ etter henholdsvis tre og to år med medikamentet. Det var også en signifikant økning i totaloverlevelse etter tre år med trastuzumab - fra 91,7\% til 94,3\% $(31,32)$.

Dagbladet skrev at flere onkologer mente behandlingseffekten var så overbevisende at de anså det som uaktuelt å vente med å ta $i$ bruk medikamentet. Overlege Wist ved Ullevål universitetssykehus uttalte at livstidskostnaden for medikamentet per kvinne ville være 370000 kroner og at trastuzumab ville redde livet til ca. 75 av 330 kvinner med HER2-positiv brystkreft. Ut fra dette kalkulerte han at det ville koste 1,1-1,2 millioner kroner per spart kvinneliv, en pris han mente var akseptabel (33).

Finansieringssystemet ble også i denne saken nevnt som en barriere for at sykehusene kunne innføre medikamentet (33). I august 2005 kontaktet Foreningen for brystkreftopererte helseministeren og ba om midler til trastuzumab. Helseministeren ville ikke bevilge ekstratilskudd til trastuzumab på grunn av at det allerede var gitt 18 millioner kroner i «ekstraordinært tilskudd» til innføringen av cetuximab. Helse- og omsorgsdepartementet nektet å prioritere trastuzumabsaken spesielt, slik som de hadde gjort i cetuximabsaken et halvt år tidligere. Flere kreftavdelinger var uenige i det politiske vedtaket om å tilby cetuximab og omprioriterte. De valgte å la være å tilby cetuximab og heller tilby trastuzumab $(30,33)$.

I Kunnskapssenterets helseøkonomiske rapport fra 2006 anslås det at innføringen av trastuzumab i Norge vil koste - ut fra et helsetjenesteperspektiv - rundt 100 millioner kroner, levealderen i pasientgruppen forventes $\mathrm{i}$ gjennomsnitt å bli forlenget med 2,7 år, og kostnad-nytte-ratioen er 72000 kroner per vunnet leveår. Kunnskapssenteret anslo at behandlingen ville være aktuell for om lag 300 pasienter i Norge per år (29). Norum og medarbeidere kom fram til en kostnad-nytteratio av trastuzumab på $64500-382800 /$ NOK/QALY (34).

\section{Evaluering av innføringen av trastuzumab}

Apenhet. Legene har stor beslutningsmakt i slike avgjørelser, og dette begrenser muligheten for en bred og åpen prosess. På bakgrunn av avisoppslagene virker det som om mange kreftavdelinger hadde innført trastuzumab allerede før forespørselen om ekstra bevilgninger ble sendt, og at denne beslutningen ble tatt internt i sykehusene. Beslutningen i Helse Nord (og dens rasjonale) om midlertidig å stanse bruken av trastuzumab var heller ikke offentlig tilgjengelig.

Relevans. Ved kreftavdelingene der man valgte å ta i bruk trastuzumab før de regionale helseforetakene hadde tatt en endelig avgjørelse, ble dette begrunnet med at effekten var så god at de ikke kunne nekte pasientene denne behandlingen. Onkologene mente at kostnadene var lave nok til å kunne forsvares i behandlingen av brystkreft.

Brystkreft er en alvorlig sykdom, men alvorlighetsgraden var ikke noe avgjørende argument for å tilby behandlingen. Trastuzumab er aktuelt i tidlig fase, da overlevelse og livskvalitet er bedre enn senere i sykdomsforløpet.

Klageadgang og korreksjon. Det er vanskelig å klage på prioriteringsbeslutninger som blir tatt internt i fagmiljøene og der verken beslutningene eller rasjonalet er offent-

Tabell 1 Fire relevante prioriteringskriterier som er nedfelt i Lønning II-rapporten, prioriteringsforskriften og pasientrettighetsloven (15-17)

\begin{tabular}{ll} 
Kriterium & Spørsmål \\
\hline Alvorlighetsgrad & Er tilstanden alvorlig nok? \\
\hline Effektivitet & Er behandlingen effektiv nok? \\
Kostnadseffektivitet & Er behandlingen rimelig kostnadseffektiv? \\
\hline Kvalitet på evidens & Er dokumentasjonen for de tre første punktene tilfredsstillende?
\end{tabular}

Tabell 2 Rammeverket «ansvar for rimelige begrunnelser». Fire minimumskrav til en rettferdig, deliberativ prosess $(9,18)$

\begin{tabular}{ll} 
Krav & Beskrivelse \\
Åpenhet & $\begin{array}{l}\text { Beslutninger som begrenser tilgang til helsetjenester skal være offent- } \\
\text { lige, og begrunnelsene skal være offentlig tilgjengelige }\end{array}$ \\
\hline Relevans & $\begin{array}{l}\text { Begrunnelsene skal være relevante. Det vil si at de må hvile på faglig } \\
\text { dokumentasjon, grunner og prinsipper som alle parter - administrato- } \\
\text { rer, klinikere, pasienter og samfunnsborgere - kan akseptere som } \\
\text { relevante for à avgjøre hvordan forskjellige behov for helsetjenester } \\
\text { kan tilfredsstilles for hele befolkningen, gitt ressursknapphet }\end{array}$
\end{tabular}

Klageadgang Det bør eksistere mekanismer for klager og kritikk av avgjørelser hvor og korreksjon det er uenighet om beslutninger som begrenser tilgangen til helsetjenester, inkludert mulighet for å revidere beslutninger i lys av ny dokumentasjon eller nye argumenter

Regulering og institu- Det bør være offentlig eller frivillig regulering av de mekanismer og sjonalisering prosedyrer som sikrer at de tre foregående krav blir oppfylt 
sen om trastuzumab ble tatt av fagmiljøet. Helse- og omsorgsdepartementet hadde ikke lagt til rette for åpne og eksplisitte beslutningsprosedyrer. Helseministerens rasjonal bak beslutningen om å innføre cetuximab var ikke tilgjengelig. Offentligheten står derfor fritt til å spekulere i om den egentlige årsaken var å legge mest vekt på de dårligst stilte eller om helseministeren vegret seg for å ta et vanskelig valg. Sluttresultatet - etter en implisitt og lukket prosess hvor det ikke var klare ansvarsforhold mellom faglig, administrativ og politisk ledelse - ble at onkologiske avdelinger omprioriterte og valgte å tilby trastuzumab fremfor cetuximab.

I internasjonal prioriteringsdebatt er det de siste årene lagt mye vekt på legitime prosedyrer for ressursfordeling (35-37). «Ansvar for rimelige begrunnelser» er foreløpig det mest anerkjente rammeverket for legitime beslutninger, det blir blant annet brukt av NICE og på sykehusnivå i Canada $(18,38-40)$. Implementering av disse fire kravene vil innebære at dagens ofte lukkede prioriteringspraksis erstattes med mer krevende åpne og ansvarlige prioriteringer i helsetjenesten (41).

Rammeverket er en standard for nødvendige institusjonelle endringer for et bedre prioriteringssystem (37). Gjentatte rettferdige, deliberative prosesser for saker som likner hverandre etablerer normer for likebehandling (42). En rettferdig prosess åpner opp for læring om prioritering på flere nivåer innad i institusjoner, blant klinikere, pasienter og alle samfunnsborgere (18). Representativitet blir forsøkt ivaretatt $\mathrm{i}$ «ansvar for rimelige begrunnelser» ved at alle berørte parter har mulighet til å påvirke og fremme klage på de beslutninger som blir tatt. Prioriteringsbeslutninger skal også revideres i lys av ny dokumentasjon eller nye argumenter. Her kan vi lære mye fra Sverige og England, som er kommet lenger i denne prosessen. NICE utvikler retningslinjer og forsøker å bruke disse som eksplisitte prioriteringsverktøy. De offentliggjør klare beslutninger, hvem som deltar i prosessen og begrunnelsen for anbefalingene. NICE inkluderer også «borgerråd» (citizens councils) med bredt sammensatte grupper som uttaler seg om verdispørsmål. Legitime kliniske retningslinjer kan bidra til mer samstemt og rettferdig grensesetting. Kunnskapssenteret kan styrke og medvirke til dette ved å utarbeide systematiske evalueringer av effekt og kostnad-nyttevurderinger som utgangspunkt for åpne, deliberative prosedyrer.

Den offentlige prioriteringsdebatten kom for sent i disse sakene. Dette kan endres. Kunnskapssenterets nye database Mednytt (www.mednytt.no) er lovende i så henseende. Helse- og omsorgsdepartementet er i Nasjonal helseplan (2007-2010) pålagt å utrede etableringen av et nasjonalt system som kan håndtere innføringen av ny teknologi (4). Vi mener at et slikt system bør sørge for at det settes legitime grenser for ny teknologi og sikre at beslutningene tilfredsstiller de fire kravene til legitime prosesser.
Det er vanskelig å få plass til nye, kostnadskrevende intervensjoner innenfor budsjettrammene, og finansieringssystemet ble nevnt som en barriere ved innføringen av begge medikamentene. Innsatsstyrt finansiering dekker $40 \%$ av de beregnede gjennomsnittskostnader. Det er ikke på grunn av manglende revisjon av DRG-vekter at utgiftene må dekkes av det enkelte sykehus eller avdeling. Størstedelen av finansieringen fordeles i rammebudsjetter som er rimelig forutsigbare fra år til år. De regionale helseforetakene blir nødt til å finne mekanismer for finansiering og prioritering av ny og kostbar teknologi. Hvis de velger å tilby ny, kostnadskrevende behandling, må dette delvis finansieres gjennom rammebudsjettet. Annen helsehjelp må da nedprioriteres.

\section{Konklusjon}

På det tidspunkt cetuximab (Erbitux) og trastuzumab (Herceptin) ble innført, var det ikke etablert institusjoner eller gode mekanismer for en åpen og eksplisitt prioriteringsprosess på regionalt eller nasjonalt nivå der hensynet til legitim uenighet kunne bli ivaretatt. Slike mekanismer bør innføres nasjonalt og i samarbeid med de regionale helseforetakene. Nasjonalt råd for kvalitet og prioritering i helsetjenesten kan være rette forum for slike verdivalg og bør ha ansvar for at det etableres åpne prosesser for prioritering.

Vi takker Berit Mørland, Olav Valen Slåttebrekk, Biørn Guldvog, John-Arne Røttingen, Stein Evensen, Erik Wist, Ivar Sønbø Kristiansen, Jan Abel Olsen og Frode Lindemark for gjennomlesing av manuskriptet og gode kommentarer.

Oppgitte interessekonflikter: Ole Frithjof Norheim har hatt lønnet arbeid relatert til prioritering for Helse- og omsorgsdepartementet, Helsedirektoratet, Kunnskapssenteret og Helse Vest. Kjell Arne Johansson og Ingrid Miljeteig har ingen oppgitte interessekonflikter.

\section{Litteratur}

OECD health data 2007. Paris: OECD Publishing 2007

2. Lang, lang rekke - hvem skal vente, hvem skal få? Oslo: Den Norske Lægeforening, 2007.

3. Rapport Nasjonal strategigruppe for prioriteringer. Oslo: Helse Nord, Helse Midt-Norge, Helse Vest, Helse Øst, Helse Sør, 2006

4. Nasjonal helseplan (2007-2010). Oslo: Helse- og omsorgsdepartementet, 2006.

5. Klein R. Rationality and rationing: diffused or concentrated decision-making? I: Tunbridge T, red. Rationing of health care in medicine. London: Royal College of Physicians of London, 1993: 73-82.

6. Klein R. Dimensions of rationing: who should do what? BMJ 1993; 307: 309-11.

7. Klein R, Day P, Redmayne S. Rationing in the NHS the dance of the seven veils - in reverse. Br Med Bull 1995: 51: 769-80.

8. Daniels N, Sabin JE. Setting limits fairly: can we learn to share medical resources? Oxford: Oxford University Press, 2002

9. Norheim OF. Hva hindrer åpenhet om prioriteringer? Tidsskrift for velferdsforskning 2005; 8 : 34-42

10. Helseøkonomi i Bergen (HEB). http://heb.rok kan.uib.no/ (20.11.2007).

11. Institutt for helseledelse og helseøkonomi, Universitetet i Oslo. www.med.uio.no/heled/ (20.11.2007).
12. Kristiansen IS. Prioritering er mer enn å ordne køen. Tidsskr Nor Lægeforen 2007; 127: 2278.

13. Kristiansen IS, Gyrd-Hansen D. Prioritering og helse - bør det innføres makspris på leveår? Tidsskr Nor Lægeforen 2007: 127: $54-7$.

14. Daniels N. Accountability for reasonableness. BMJ 2000; 321: 1300-1

15. Norges offentlige utredninger. Prioritering på ny. Gjennomgang av retningslinjer for prioriteringer innen norsk helsetieneste NOU 1997. 18

16. Lov om pasientrettigheter av 2. juli $1999 \mathrm{nr} 63$ (pasientrettighetsloven). Oslo: Sosial- og helsedepartementet, 1999

17. Forskrifter om prioritering av helsetjenester og rett til helsehjelp, ventelisteregistrering og reiseutgifter ved fritt sykehusvalg. Oslo: Sosial- og helsedepartementet, 2000

18. Daniels N, Sabin J. Setting limits fairly. Can we learn to share scarce medical resources? Cambridge: Oxford University Press, 2002

19. Yin R. Case study research: design and methods 2. utg. Thousand Oaks, CA: Sage Publications, 2003.

20. Miller W, Crabtree B. Clinical research. A multimethod typology and qualitative roadmap. I: Crabtree B, Miller W, red. Doing qualitative research. 2. utg. Thousand Oaks, CA: Sage Publications, 1999: $20-4$

21. Hafstad A. Første dose med ny kreftmedisin. Aftenposten 3.5.2005

22. Cunningham D, Humblet $Y$, Siena $S$ et al. Cetuximab monotherapy and cetuximab plus irinotecan in irinotecan-refractory metastatic colorectal cancer. N Engl J Med 2004: 351: 337-45.

23. Olderkjær O. Dyr kreft-medisin til fleire. Bergens Tidende 19.2.2005.

24. Jansen K. Kreften ga kraft til å hjelpe. Bergens Tidende 17.4.2005.

25. Prosjekt 366 - bevacizumab og cetuximab ved metastaserende kolorektalcancer. Oslo: Nasjonal kunnskapssenter for helsetjenesten, 2007.

26. Norum J. Cetuximab in the treatment of metastatic colorectal cancer: a model-based cost-effectiveness analysis. J Chemother 2006; 18: 532-7.

27. Norheim OF. Hvor mye vil samfunnet betale? Tidsskr Nor Lægeforen 2003; 123: 303

28. Jonker D, O'Callaghan C, Karapetis C et al. Cetuximab for the treatment of colorectal cancer. $N$ Eng J Med 2007; 357: 2040-8.

29. Ny medikamentell behandling av brystkreft. Oslo: Nasjonalt kunnskapssenter for helsetjenesten, 2006.

30. Bore M. Kamp om kostbare kreftkurer. Stavanger Aftenblad 12.11.2005

31. Piccart-Gebhart M, Procter M, Leyland-Jones B et al. Trastuzumab after adjuvant chemotherapy in HER2-positive breast cancer. N Engl J Med 2005; 353: $1659-72$.

32. Romond E, Perez E, Bryant J et al. Trastuzumab plus adjuvant chemotherapy for operable HER2 positive breast cancer. N Engl J Med 2005; 353: 1673-84.

33. Solend P. Syke penger. Dagbladet 26.7.2006.

34. Norum J, Olsen JA, Wist EA et al. Trastuzumab in adjuvant breast cancer therapy. A model based costeffectiveness analysis. Acta Oncol 2007; 46: 153-64.

35. Coulter A, Ham C, red. The global challenge of health care rationing. London: Open University Press, 2000.

36. Holm S. The second phase of priority setting. Goodbye to the simple solutions: the second phase of priority setting in health care. BMJ 1998; 317: 1000-2.

37. Ham C. Tragic choices in health care: lessons from the child B case. BMJ 1999; 319: 1258-61.

38. National Institute for Health and Clinical Excellence. Principles for the development of NICE guidance (final report). London: NICE, 2005

39. Martin D, Pater J, Singer P. Priority-setting decisions for new cancer drugs: a qualitative case study. Lancet 2001; 358: 1676-81.

40. Rawlins M. Pharmacopolitics and deliberative democracy. Clin Med 2005; 5: 471-5.

41. Holm S. Developments in the Nordic countries goodbye to the simple solutions. I: Coulter A, Ham $C$, red. The global challenge of health care rationing. London: Open University Press, 2000.

42. Ham C, Coulter A. Where are we now? I: Coulter A Ham C, red. The global challenge of health care rationing. London: Open University Press, 2000.

Manuskriptet ble mottatt 12.12. 2007 og godkjent 24.9. 2008. Medisinsk redaktør Trine B. Haugen. 